\title{
Development of the science of mass casualty incident management: reflection on the medical response to the Wenchuan earthquake and Hangzhou bus fire*
}

\author{
Wei-feng SHEN ${ }^{\dagger}$, Li-bing JIANG, Guan-yu JIANG, Mao ZHANG, Yue-feng MA, Xiao-jun $\mathrm{HE}^{\dagger \ddagger}$ \\ (Department of Emergency Medicine, the Second Affiliated Hospital, School of Medicine, Zhejiang University, Hangzhou 310009, China) \\ †E-mail: swfzlj@163.com; hexiaojun_hz@163.com \\ Received Aug. 11, 2014; Revision accepted Nov. 6, 2014; Crosschecked Nov. 21, 2014
}

\begin{abstract}
Objective: In this paper, we review the previous classic research paradigms of a mass casualty incident $(\mathrm{MCl})$ systematically and reflect the medical response to the Wenchuan earthquake and Hangzhou bus fire, in order to outline and develop an improved research paradigm for $\mathrm{MCI}$ management. Methods: We searched PubMed, EMBASE, China Wanfang, and China Biology Medicine (CBM) databases for relevant studies. The following key words and medical subject headings were used: 'mass casualty incident', 'MCl', 'research method', 'Wenchuan', 'earthquake', 'research paradigm', 'science of surge', 'surge', 'surge capacity', and 'vulnerability'. Searches were performed without year or language restriction. After searching the four literature databases using the above listed key words and medical subject headings, related articles containing research paradigms of $\mathrm{MCl}, 2008$ Wenchuan earthquake, July 5 bus fire, and science of surge and vulnerability were independently included by two authors. Results: The current progresses on $\mathrm{MCI}$ management include new golden hour, damage control philosophy, chain of survival, and three links theory. In addition, there are three evaluation methods (medical severity index (MSI), potential injury creating event (PICE) classification, and disaster severity scale (DSS)), which can dynamically assess the $\mathrm{MCl}$ situations and decisions for $\mathrm{MCl}$ responses and can be made based on the results of such evaluations. However, the three methods only offer a retrospective evaluation of $\mathrm{MCl}$ and thus fail to develop a real-time assessment of $\mathrm{MCl}$ responses. Therefore, they cannot be used as practical guidance for decision-making during $\mathrm{MCl}$. Although the theory of surge science has made great improvements, we found that a very important factor has been ignored—vulnerability, based on reflecting on the $\mathrm{MCl}$ response to the 2008 Wenchuan earthquake and July 5 bus fire in Hangzhou. Conclusions: This new paradigm breaks through the limitation of traditional research paradigms and will contribute to the development of a methodology for disaster research.
\end{abstract}

Key words: Mass casualty incident, Surge, Vulnerability, Earthquake, Fire incident doi:10.1631/jzus.B1400225 Document code: A CLC number: R129

\section{Introduction}

World Health Organization (WHO) defines disasters as "any occurrence, which causes damage,

\footnotetext{
"Corresponding author

* Project supported by the Research Fund of Ministry of Health of China (No. N20080022), the Major Science and Technology Project of Zhejiang Province (No. 2009C03010-3), the Medical Scientific Research Foundation of Zhejiang Province (No. 200921012), and the Educational Commission of Zhejiang Province (No. Y200908921), China (Di) ORCID: Wei-feng SHEN, http://orcid.org/0000-0002-7493-897X; Xiao-jun HE, http://orcid.org/0000-0001-5968-4206

(C) Zhejiang University and Springer-Verlag Berlin Heidelberg 2014
}

ecological disruption, loss of human life, and deterioration of health and health services, on a scale sufficient to warrant an extraordinary response from outside the affected community or area" (Rathbun and Cranmer, 2006). A disaster is defined by the Emergency Management and Disaster Medicine (EMDM) Academy Consensus Group as an event in which the medical need exceeds the response capabilities in the affected area, mainly due to a large number and/or severity of injured or ill victims. This imbalance can be due to a quantitative and/or a qualitative shortage of resources (personnel and materials), 
but also to organizational or operational shortcomings The word 'disaster' is used as a synonym for 'emergency' and 'mass casualty incident/event' (Debacker et al., 2012). Meanwhile, in the studies of Aylwin et al. (2006) and Adini et al. (2010), a mass casualty incident (MCI) is any incident in which emergency medical services and resources, such as staff and equipment, are overwhelmed by the number and severity of casualties. Official figures (as of July 21, 2008, 12:00 Central Standard Time (CST)) state that 69227 were confirmed dead, 374643 injured, and 17923 listed as missing in the 2008 Wenchuan earthquake (Zhang et al., 2012). The number of those killed or missing is reported to be more than 23000 in the 2011 Tohoku earthquake (Nagamatsu et al., 2011) Due to such extensive casualties and massive destruction of social properties, a need for improving MCI response capability is in urgent demand (Hamilton et al., 2009). Recently, the science of surge (medical surge response capability (MSRC) can be influenced by surge and surge capacity) has been employed for the research of MCI response capability (Kaji et al., 2006; Dayton et al., 2008; Peleg and Kellermann, 2009). The dynamic quantitative comparison between surge and surge capacity used in the science of surge provides a foundation for the exploration of MCI response capability. The science of surge is especially beneficial in MCI where medical needs are clearly clarified. Yet, its limitations have been shown in dealing with MCI where the boundary of medical demands in the early stages of a calamity is unclear and the circumstance for responding is extremely serious, such as the 2008 Wenchuan earthquake. By thoroughly investigating the current researches on MCI and emergency medical responses in the 2008 Wenchuan earthquake and applying the science of surge into the investigation, this paper is aimed at outlining and developing an improved research paradigm for MCI management.

\section{Review of previous research paradigms}

MCI is an incident, which causes many casualties beyond the local medical capacity (Einav et al., 2006). A major disaster leading to an MCI results in huge loss of properties and massive destruction of social structures in the local area. Thus in addition to the suffering of a direct disaster attack, a local medi- cal response system is subjected to a tremendous medical surge beyond its capacities. Compared with deaths and injuries caused by conventional emergencies, an MCI has two characteristics (Rega et al., 2009). First, the large number of casualties in an MCI causes a gigantic medical need far in excess of available resources, including rescue equipment, logistic supply, and personnel. Secondly, dangerous environmental conditions during the time of a disaster often restrain full medical responses. An MCI medical response cycle includes four phases: search and rescue, triage and initial treatment, evacuation, and definitive treatment (Goh, 2009). The current progresses on MCI management include the following: (1) new golden hour (Newgard et al., 2010): the 'new' golden hour may well be the time in the operating room before a patient reaches the physiologic limit, defined as the onset of the triad (hypothermia, acidosis and coagulopathy); (2) damage control philosophy (Cirocchi et al., 2010): damage control is most commonly understood to apply to surgical procedures, where a limited resource (the patient's physiological reserve) is conserved by abbreviating an operation to the minimum procedure that will save a life, and the principle of damage control can be applied to all aspects of the major incident response; (3) chain of survival (Marchant et al., 2008): survival after severe trauma may depend on a structured chain of care from the management at the scene of trauma to hospital care and rehabilitation; and, (4) three links theory (Jiang et al., 2005): the three links theory applied in a trauma emergency care system refers to an integrated system with three important components of a trauma emergency care system, viz. pre-hospital trauma services, hospital trauma services, and critical care services. All of these developments could improve the outcomes for patients. However, the progress of MCI response research has been slow. With limited time and resources in an $\mathrm{MCI}$, a quantitative evaluation method to dynamically assess the MCI situation is needed and decision-making for MCI responses should be based on the results of such evaluations. Currently, three such evaluation methods for MCI assessment are available, including medical severity index (MSI) (de Boer et al., 1989), potential injury creating event (PICE) classification (Koenig et al., 1996), and disaster severity scale (DSS) (Ferro, 2005). The introduction of MSI made it possible to immediately assess the medical size of a disaster. The three 
following parameters are needed to quantify a disaster. (1) Casualty load $(N)$, the number of casualties in a disaster. (2) The severity of the incident $(S)$. Patients treated at the scene by the simple triage and rapid treatment (START) program are divided into four classes: T1, life-threatening cases demanding immediate attention; T2, non-life-threatening cases requiring hospital treatment; T3, casualties not necessarily requiring hospitalization but rather less demanding single point care; and DOA, the dead and the dead-on-arrival. The severity of the incident is expressed as $S=(\mathrm{T} 1+\mathrm{T} 2) / \mathrm{T} 3$. (3) The total capacity (TC) of medical services. TC in the medical assistance chain is composed of medical rescue capacity (MRC), medical transport capacity (MTC), and hospital treatment capacity (HTC). Once $N, S$, and TC of the medical services are quantified, the MSI, calculated as $(N \times S) / \mathrm{TC}$, can be defined. An MSI of $>1$ is indicative of a disaster. An MSI can be applied to evaluate the disaster itself and estimate the medical requirements in the disaster preparedness phase. The proposed methodology is of practical importance for handling disasters. Assessment of PICE nomenclature (PICE stage: 0, I, II, III) is based on the following parameters: (1) status of event: static, dynamic; (2) status of resources: controlled, disruptive, paralytic; (3) degree of effect: local, regional, national, international; (4) projected need for outside aid: little to none, small, moderate, great; (5) status of outside help: inactive, alert, standby, dispatch. In an attempt to classify and assess disasters, a DSS was developed. The assessment of the DSS is based on the following parameters: (1) the effect on the surrounding community; (2) classification of disasters based on origin; (3) impact time; (4) radius of impact sit; (5) the number of casualties requiring medical treatment; (6) average severity of the injuries sustained; and, (7) the medical rescue time: rescue, primary treatment, and transportation. The classification scheme is based on these variables, which are directly related to either the origin or the effect of disasters. By quantifying or weighing these variables and summing the individual scores, a DSS can be constructed, which normally runs from 1 to 13. A limitation of the practical use of this scoring system is that it can only be applied retrospectively. However, the three methods are designed to offer a retrospective evaluation of $\mathrm{MCI}$ and thus fail to develop a real-time assessment of an MCI response. Therefore, they cannot be used as a practical guidance for decision-making during an MCI.

Because of the scarcity, non-replicability, and high risk of catastrophes, current researches on the theories and methods for MCI response evaluations are based on catastrophe modeling (Leiba et al., 2009). Takahashi et al. (2007) proposed an assessment model for MCI responses. In this model, the medical response capacity is divided into MRC, MTC, and HTC, in which the least capacity is the dominant one. At present, many incident decision-making systems have been developed through computer technology, such as an emergency management system (EMS) in the USA, the major emergency management (MEM) brain in the UN, and the disaster response system (DRS) in Japan, etc. Simulation research on MCI responses is on the rise as well. Hirshberg et al. (1999) used simulation technology to analyze hospital emergency resource utilization plans for MCI due to urban terrorist bombings. Based on hospital resource conditions and the assumption that medical care quality is not affected, and with the evaluation of injury severity of the wounded, the simulation could predict the hospital's medical response capacities and its major bottlenecks in handling critical casualties. Hupert et al. (2007) proposed a simulation model of mass casualty trauma care, which involved a series of key indicators. Based on a large number of traumatic death cases, the model can quantitatively study various factors involved in MCI responses and help decision makers to find the best plans for medical emergency incidents in the shortest time period. Lerner et al. (2010) used a simulated MCI to verify the validity of the procedure of SALT (sort, assess, lifesaving interventions, treatment and/or transport) triage. Though advanced simulation technology was used, the structure in this MCI emergency model is too simple, and essential factors under concern are insufficient, especially the underestimated dynamic changes of medical surge and surge capacity. More importantly, the boundary setting in the model, which is within the capacity of medical resources, is not appropriate for studying an MCI such as the 2008 Wenchuan earthquake. In the science of surge, surge and surge capacity may exhibit quantitative changes in a time series. Surge is defined as a significant increase in medical demand in a short period during a disaster, which goes beyond ordinary medical capacity, leading to a need in using reserved resources or starting non-routine medical systems. Surge includes influx of 
casualties (volume rate), event (type, scale, and duration), and resource demand (consumption and degradation) (Hick et al., 2004). Surge capacity is the ability of medical care system to expand quickly to meet such medical surges. Surge capacity consists of four components (Kelen et al., 2006): system (integrity), space (size, quality), staff (number, skill), and supplies (quantity, quality). In the science of surge, the dynamic comparison of surge and surge capacity plays a foundational role for the study of MCI management under two boundary conditions - finite time and limited resources. The science of surge is well beyond the past dimensions for describing $\mathrm{MCI}$ management, giving full consideration to a variety of elements involved in disaster responses using the two perspectives - surge and surge capacity. In the aspect of surge capacity, Hick et al. (2008) proposed the CO-S-TR model, and the medical capacity is divided into three subsystems, each consisting of four elements. ' $\mathrm{CO}$ ' is primarily emergency management, consisting of command, control, communication, and coordination. ' $\mathrm{S}$ ' is mainly the demand for response, including staff, stuff, space, and special. 'TR' mainly refers to the transport and treatment of the wounded, including tracking, triage, treatment, and transportation In this model, Hick et al. (2009) proposed a further refined model of surge capacity composed of conventional capacity, contingency capacity, and crisis capacity. This model with a tiered progressive description is more practical in the pre-crisis intervention for $\mathrm{MCI}$ response. In the science of surge, an important indicator of MCI response is MSRC. MSRC refers to the ability for surge capacity to meet surge (Hick et al., 2004). MSRC can be calculated as MSRC=planning $\times$ surge capacity/surge (Jenkins et al., 2006; Kelen and McCarthy, 2006).

The introduction of this formula represented a great progress, but there is an unsolved problem: classical surge theory cannot explain why two similar surge capacities dealing with similar disasters show different endings.

\section{Reflection on the $\mathrm{MCl}$ response to the Wenchuan earthquake and Hangzhou bus fire, and the development of the science of surge}

As the largest MCI since the founding of the People's Republic of China, the 2008 Wenchuan earthquake is a comprehensive examination of a disaster response system in this country. Wenchuan County is located in the northwest part of the Sichuan basin. The county has a population of 111788 , and more than $25 \%$ of the population are ethnic minorities (Qiang). There are 25 health institutions, and the number of currently available sickbeds is 252 , equipped with 304 health technical personnel. After the Wenchuan earthquake, the Chinese government mobilized the whole country, activated the emergency medical rescue system within $2 \mathrm{~h}$, and ordered 10630 medical workers to the affected areas. At the same time, the Chinese government established an earthquake relief headquarters, and the Chinese Disaster Relief Committee and the Ministry of Civil Affairs initiated a class I natural disaster response. The total number of earthquake rescue participants reached 175000 , including 157000 soldiers and 18000 people from a variety of professional rescue teams. In addition, 9670 vehicles and 193 helicopters were put into use (Zhang et al., 2012). On the whole, the total number of the injured was over 374000 , about 87000 were rescued, including 70000 rescued by first aid, 10000 by the army, and 7439 by professional rescue teams (Shen et al., 2012). The Wenchuan earthquake rescue demonstrated that the disaster surge capacity of the nation was huge, but two problems should not be ignored. Firstly, rescue efforts were ineffective in the initial response and the in-hospital mortality due to the earthquake was high. According to the statistics, only $19.3 \%$ of the injured in the earthquake were admitted within $24 \mathrm{~h}$ into the Wenchuan County hospital located in the epicenter (Zhou et al., 2008). During the Wenchuan earthquake, 3484 of the 96000 total casualties cared for in the hospital died (Jiang et al., 2008). Secondly, the accuracy and timeliness of the casualty information in the affected area were not satisfactory, leading to the inappropriate deployment of rescue forces- 'empty nest' (no deployment of rescue forces) in certain disaster areas and 'overflowing' (the deployment of rescue forces exceeding the demand) in others. The 2008 Wenchuan earthquake epicenter was located in Wenchuan County, but the most severely damaged areas were concentrated in fault zones (Zhang et al., 2009). Although advanced assessment technologies such as satellite remote sensing have been used, lack of a set of useful theories and assessment methods for the whole process of an MCI gave rise to deviations in the spatial 
and temporal distribution of resources during the initial hours after the MCI when medical needs were not clear. More importantly, the variation in vulnerability of a hazard bearing body in different disaster regions led to the differences in surge and surge capacity among areas attacked by the same disaster. This is illustrated in different severities in various regions affected by the 2008 Wenchuan earthquake (Chen et al., 2012): (1) concerning surge, the ratio between mortality in severely affected areas $(1788 / 100000)$ and that in mildly affected areas $(1.23 / 100000)$ was 1453.65 ; (2) concerning the relative surge capacity for managing the surge, the ratio between the ratio of the injured and health personnel in severely affected areas $(1 / 0.07)$ and that in mildly affected areas (1/100.79) was 1439.85 ; and, (3) concerning the dimension of vulnerability, the ratio between the percentage of medical institutions collapsed in severely affected areas $(67.45 \%)$ and that in mildly affected areas $(1.10 \%)$ was 61.31 . These data illustrate the plight of a large surge, with relatively unmatched surge capacity and even worse, huge loss of surge capacity due to vulnerability during the disaster. Unconventional MCIs such as the 2008 Wenchuan earthquake cannot be studied comprehensively when simply based on the analysis of surge and surge capacity. In fact, the vulnerability should be considered in the study of MCI responses as well. Research on vulnerability has already been carried out earlier in the field of formation mechanism in disaster occurrence. Blaikie et al. (1994) proposed the disaster pressure and release model, which constituted an interaction between hazard and vulnerability. The relationship is expressed as a simple equation of $D=H+V$, where $D$ is for disaster, $H$ for hazard, and $V$ for vulnerability. Kenneth (1997) proposed a catastrophe model involving four elements: hazard, vulnerability and adaptability, dangerous interference conditions, response and adjustment measures. According to these models, vulnerability has been considered as the core element of a hazard bearing body suffered due to a disaster. During an MCI, the pressure is not simply from surge. Due to the vulnerability of a hazard bearing body, the loss of response resources and the degradation of the environment responding to the MCI re-impose a direct impact on surge capacity, whose effect is even harsher than that of the lack of response resources.

This is reflected specifically in the 2008 Wen- chuan earthquake. Firstly, Wenchuan County has a population of 111788 and covers an area of 4083 square kilometers. Such a high population density leads to a large proportion of population exposed to the earthquake. More and more young people work in eastern China, and people staying in the county are mainly children and the elderly, which are vulnerable to an earthquake disaster. Students accounted for about $7 \%$ of the deaths in the Sichuan Province and people older than 60 years also accounted for a large proportion of the dead. Secondly, Wenchuan County is located in mountainous areas, and mainly depends on the limited number of mountain roads linking the Chengdu Plain. When the earthquake occurred, the strong intensity of the epicenter caused serious casualties and the collapse of most buildings, which together with a lack of on-the-spot rescue made the rescue work very difficult. As a result, medical teams could not reach the earthquake center until $52 \mathrm{~h}$ after the Wenchuan earthquake. Thirdly, Wenchuan County is located in the northwestern part of the Sichuan Basin in China. Local economic development is far below the level of cities in eastern China. Standards for the earthquake resistance of buildings are generally poor. As a result, schools were heavily hit and about $10243(80 \%)$ medical institutions in Sichuan were damaged. In ten badly damaged areas within the disaster zone, the collapse rate of medical buildings was $67.5 \%$ (Zhang et al., 2012). The earthquake even caused the Beichuan County and the Yingxiu Township of Wenchuan County to be razed to the ground. Construction of emergency shelters was rare in most cities, except in Chengdu. Other preparations for large disasters, such as plans to ensure that the communication, transportation, and facilities stayed functional and that materials including food and medicine were in stock, were all insufficient. Before the earthquake, the Wenchuan County People's Hospital was responsible for the main medical and health tasks (200 beds, 173 medical personnel, 11 surgeons, and 6 operating rooms). After the earthquake, the buildings of this hospital were completely destroyed. Medical treatment services could only be provided with a shortage of and even lack of water, electricity, space, equipments, medicine, and food, etc. A large number of casualties were treated in tents. Medical staffs were in a state of exhaustion due to a lack of rest and food for a long time. The hospital had lost the ability as a secondary hospital to treat the 
wounded (Zhou et al., 2008). Fourthly, government departments in charge of services such as transport, communication, education, and media underestimated the risk of earthquakes in the region and generally were not well prepared. This earthquake fully exposed the region's poor risk-awareness, inadequate disaster prevention plans, inability to warn disasterrelated government departments, and scarcity of training for escape, self-help, and first-aid (Zhang et al., 2012). In addition to the above, most people speak different dialects in the county, and more than $25 \%$ of the population are ethnic minorities (Qiang), so the communication between the wounded and medical staff was difficult. External response for medical support to the affected areas during the early stage after the earthquake was rapid, but the reliefconstrained environment restricted the disaster response process.

This situation is also reflected specifically in the bus fire incident in Hangzhou on July 5, 2014. The bus fire incident resulted in 32 casualties, and 29 of them were received into the hospital, with 15 casualties having severe burns (nearly $50 \%$ of the severely injured patients), including three children (http://news. xinhuanet.com/legal/2014-07/07/c_126717614.htm). The wounded mortality was zero in the phase of rescue at the scene and during pre-hospital care. It was attributed to the implementation of broad public participation in the emergency rescue at the scene and during pre-hospital care. This shows that the population in Hangzhou representing a medium-sized city in China, already has a preliminary sense of their relief and primary rescue capabilities. In other words, these people were not at the low level of disaster vulnerability. Thus, vulnerability is known as an important consideration factor of disaster and emergency response as shown in this case. The difference in regional healthcare response capabilities can be observed from different regional vulnerabilities in this same MCI. Hence, in addition to surge, surge capacity and vulnerability play an important role in unconventional MCI response. Therefore, vulnerability is introduced into the measurement of surge response capability, expressed as: surge response capability= planning $\times$ surge capacity $\times$ vulnerability/surge.

In the study of disasters, different organizations and scholars have different understandings of the concept of vulnerability. In 2004, the International Strategy for Disaster Reduction (ISDR, 2004) pro- vided the following description for the concept of vulnerability: vulnerability is a state under the influence of natural, social, economic, and environmental factors or processes which can increase or decrease the sensitivity of the people in the face of disasters. Vulnerability as defined here is the state of individuals, groups, or communities in terms of their ability to cope with and adapt to any external stress, and the ability to recover. Some studies have shown that vulnerability is mainly affected by four factors. (1) Demographic characteristics: children, old people, patients, and people with disabilities are more vulnerable to damage. (2) Natural factors: the severity of earthquake disasters is affected by the natural environment; e.g., mortality may be higher, if an earthquake occurred in mountainous areas than in plain areas. (3) Economic factors: in developing countries, it might seem that poverty and vulnerability to environmental hazards go hand in hand. On the one hand, family income level and the economic conditions in the region determine the methods of transportation, emergency supplies, and the quality of buildings. On the other hand, funds contribute to good management during and after disasters. Generally speaking, in poor areas, seismic performance of buildings is poor, especially for schools and hospitals, and in addition, other preparations for severe disasters are insufficient (for example, plans to ensure that communication, transportation, and facilities stay functional and materials including food and medicine are in stock). (4) Social factors: difference in the ability of disaster victims to prevent and prepare pre-disaster, escape during disaster, and recover post-disaster may be due to different social status and different cultural background. For example, illiterate population, due to low education level, often underestimates the seriousness of earthquakes and lacks proper knowledge concerning self-help methods. Such drawbacks indirectly contribute to the massive number of casualties and hinder the process of disaster relief (Nie et al., 2012). The influence of these four factors on vulnerability can be considered mainly in three aspects. (1) The number of people exposed to disasters: population base, population density, and population growth rate; (2) Sensitivity: this refers to the sensitivity of people to a certain intensity of earthquake shock in a particular natural, economic, and social environment, and the higher the sensitivity, the higher the vulnerability; (3) The ability to respond to disasters: the stronger the 
ability, the lower the vulnerability. Seismic vulnerability assessment is not only the basis for a long-term planning process, but also provides support for emergency decision-making in earthquake emergencies. Therefore, it is a focus in the current research on vulnerability. There are various proposed indicators and influence patterns to assess the vulnerability, primarily including macroscopic indicators (total population, proportion of the young, proportion of the old, population density, and gross domestic product (GDP) per capita, etc.) and microscopic indicators (sex, degree of education, indicators, means of communication, etc.). The latter is more accurate and more difficult to obtain (You and Zhang, 2013).

\section{A new research paradigm for $\mathrm{MCI}$ man- agement based on surge, surge capacity, and vulnerability, and its applications}

The development of a research paradigm for MCI response from two-dimensional consideration of surge and surge capacity to three-dimensional analysis of surge, surge capacity, and vulnerability is extrapolated theoretically based on the science of surge theory and the retrospective analysis of the MCI response in the 2008 Wenchuan earthquake. Two aspects should be considered to achieve this 'paradigm shift' in MCI response research: (1) the dynamic and quantitative relationship between surge capacity and vulnerability, and methods for quantitative identification and characterization of vulnerability of a hazard bearing body should be established to study MCI response; (2) the three-dimension framework of MCI management should be confirmed by more practical applications in MCIs. A key to enhance the MCI surge response capability is to improve the suitability of the MCI response planning (Ashkenazi et al., 2008). Vulnerability is very difficult to present under an ordinary status, but vulnerability of a hazard bearing body may be measured by system destruction as well as casualties after disaster attacks. According to the actually exposed vulnerability, it is necessary to improve the feasibility of MCI planning by integrating previous MCI response practices, drills, mathematical models, and simulations. There are mainly three forms of MCI response drills, including actual maneuvers, tabletop maneuvers, and field simulation drills. MCI response drills involving vulnerability will be closer to the real situation. Similarly, MCI response simulations will be upgraded with mathematical and computer models, including vulnerability. In summary, the new research paradigm for MCI management based on three-dimensional analysis of surge, surge capacity, and vulnerability breaks through the limitations of the traditional research paradigm and will contribute to the development of a new methodology in disaster research.

\section{Compliance with ethics guidelines}

Wei-feng SHEN, Li-bing JIANG, Guan-yu JIANG, Mao ZHANG, Yue-feng MA, and Xiao-jun HE declare that they have no conflict of interest.

This article does not contain any studies with human or animal subjects performed by any of the authors.

\section{References}

Adini, B., Peleg, K., Cohen, R., et al., 2010. A national system for disseminating information on victims during mass casualty incidents. Disasters, 34(2):542-551. [doi:10. 1111/j.1467-7717.2009.01142.x]

Ashkenazi, I., Kessel, B., Olsha, O., et al., 2008. Defining the problem, main objective, and strategies of medical management in mass-casualty incidents caused by terrorist events. Prehosp. Disaster. Med., 23(1):82-89. [doi:10. 1017/S1049023X0000563X]

Aylwin, C.J., König, T.C., Brennan, N.W., et al., 2006. Reduction in critical mortality in urban mass casualty incidents: analysis of triage, surge, and resource use after the London bombings on July 7, 2005. Lancet, 368(9554): 2219-2225. [doi:10.1016/S0140-6736(06)69896-6]

Blaikie, P., Cannon, T., Davis, I., et al., 1994. At Risk: Natural Hazards, People's Vulnerability and Disasters. Routledge, London, p.141-156.

Chen, Z., Shen, J., Kang, J.X., et al., 2012. Emergency medical rescue after major earthquakes: lessons from the Wenchuan earthquake. Chin. J. Evid.-Based Med., 12(4): 383-392 (in Chinese). [doi:10.3969/j.issn.1672-2531. 2012.04.004]

Cirocchi, R., Abraha, I., Montedori, A., et al., 2010. Damage control surgery for abdominal trauma. Cochrane Database Syst. Rev., 20(1):CD007438. [doi:10.1002/ 14651858.CD007438.pub2]

Dayton, C., Ibrahim, J., Augenbraun, M., et al., 2008. Integrated plan to augment surge capacity. Prehosp. Disaster Med., 23(2):113-119. [doi:10.1017/S1049023X00005719]

Debacker, M., Hubloue, I., Dhondt, E., et al., 2012. Utsteinstyle template for uniform data reporting of acute medical response in disasters. PLoS Curr., 4:e4f6cf3e8df15a. [doi:10.1371/4f6cf3e8df15a]

de Boer, J., Brismar, B., Eldar, R., et al., 1989. The medical severity index of disasters. J. Emerg. Med., 7(3):269-273. [doi:10.1016/0736-4679(89)90359-4] 
Einav, S., Aharonson-Daniel, L., Weissman, C., et al., 2006. In-hospital resource utilization during multiple casualty incidents. Ann. Surg., 243(4):533-540. [doi:10.1097/01. sla.0000206417.58432.48]

Ferro, G., 2005. Assessment of major and minor events that occurred in Italy during the last century using a Disaster Severity Scale score. Prehosp. Disaster Med., 20(5): 316-323. [doi:10.1017/S1049023X00002776]

Goh, S.H., 2009. Bomb blast mass casualty incidents: initial triage and management of injuries. Singap. Med. J., 50(1) 101-106.

Hamilton, D.R., Gavagan, T.F., Smart, K.T., et al., 2009. Houston's medical disaster response to Hurricane Katrina Part 1: the initial medical response from Trauma Service Area Q. Ann. Emerg. Med., 53(4):505-514. [doi:10.1016/ j.annemergmed.2008.10.014]

Hick, J.L., Hanfling, D., Burstein, J.L., et al., 2004. Health care facility and community strategies for patient care surge capacity. Ann. Emerg. Med., 44(3):253-261. [doi:10. 1016/j.annemergmed.2004.04.011]

Hick, J.L., Koenig, K.L., Barbisch, D., et al., 2008. Surge capacity concepts for health care facilities: the CO-S-TR model for initial incident assessment. Disaster Med. Public Health Prep., 2(S1):S51-S57. [doi:10.1097/DMP. 0b013e31817fffe8]

Hick, J.L., Barbera, J.A., Kelen, G.D., 2009. Refining surge capacity: conventional, contingency, and crisis capacity. Disaster Med. Public Health Prep., 3(S1):S59-S67. [doi:10.1097/DMP.0b013e31819f1ae2]

Hirshberg, A., Stein, M., Walden, R., 1999. Surgical resource utilization in urban terrorist bombing: a computer simulation. J. Trauma, 47(3):545-550. [doi:10.1097/0000 5373-199909000-00020]

Hupert, N., Hollingsworth, E., Xiong, W., 2007. Is overtriage associated with increased mortality? Insights from a simulation model of mass casualty trauma care. Disaster Med. Public Health Prep., 1(S1):S14-S24. [doi:10. 1097/DMP.0b013e31814cfa54]

ISDR, 2004. Living with Risk: a Global Review of Disaster Reduction Initiatives. United Nations International Strategy for Disaster Reduction (ISDR), Geneva, Switzerland.

Jenkins, J.L., O'Connor, R.E., Cone, D.C., 2006. Differentiating large-scale surge versus daily surge. Acad. Emerg. Med., 13(11):1169-1172. [doi:10.1111/j.1553-2712.2006. tb01643.x]

Jiang, G.Y., Shen, W.F., Gan, J.X., 2005. Development of the trauma emergency care system based on the three links theory. Chin. J. Traumatol., 8(5):259-262 (in Chinese).

Jiang, J.X., Wang, Z.G., Fu, X.B., et al., 2008. Experiences and rethinking on medical rescue during Chinese Wenchuan earthquake. Chin. J. Trauma, 24(8):578-579 (in Chinese). [doi:10.3321/j.issn:1001-8050.2008.08.002]

Kaji, A., Koenig, K.L., Bey, T., 2006. Surge capacity for healthcare systems: a conceptual framework. Acad. Emerg. Med., 13(11):1157-1159. [doi:10.1111/j.1553- 2712.2006.tb01641.x]

Kelen, G.D., McCarthy, M.L., 2006. The science of surge. Acad. Emerg. Med., 13(11):1089-1094. [doi:10.1111/j. 1553-2712.2006.tb01627.x]

Kelen, G.D., Kraus, C.K., McCarthy, M.L., et al., 2006. Inpatient disposition classification for the creation of hospital surge capacity: a multiphase study. Lancet, 368(9551): 1984-1990. [doi:10.1016/S0140-6736(06)69808-5]

Kenneth, H., 1997. Regions of Risk: a Geographical Introduction to Disasters. Longman, Harlow, p.14-15.

Koenig, K.L., Dinerman, N., Kuehl, A.E., 1996. Disaster nomenclature - a functional impact approach: the PICE system. Acad. Emerg. Med., 3(7):723-727. [doi:10.1111/j. 1553-2712.1996.tb03498.x]

Leiba, A., Schwartz, D., Eran, T., et al., 2009. DISAST-CIR: disastrous incidents systematic analysis through components, interactions and results: application to a large-scale train accident. J. Emerg. Med., 37(1):46-50. [doi:10.1016/ j.jemermed.2007.09.025]

Lerner, E.B., Schwartz, R.B., Coule, P.L., et al., 2010. Use of SALT triage in a simulated mass-casualty incident. Prehosp. Emerg. Care, 14(1):21-25. [doi:10.3109/1090312 0903349812]

Marchant, J., Cheng, N.G., Lam, L.T., et al., 2008. Bystander basic life support: an important link in the chain of survival for children suffering a drowning or near-drowning episode. Med. J. Aust., 188(8):484-485.

Nagamatsu, S., Maekawa, T., Ujike, Y., et al., 2011. The earthquake and tsunami-observations by Japanese physicians since the 11 March catastrophe. Crit. Care, 15(3): 167. [doi:10.1186/cc10261]

Newgard, C.D., Schmicker, R.H., Hedges, J.R., et al., 2010. Emergency medical services intervals and survival in trauma: assessment of the "golden hour" in a North American prospective cohort. Ann. Emerg. Med., 55(3): 235-246.e4. [doi:10.1016/j.annemergmed.2009.07.024]

Nie, V.J., Yang, L.S., Li, H.R., 2012. Macro assessment of seismic population vulnerability in China. Progr. Geogr., 31(3):375-382 (in Chinese).

Peleg, K., Kellermann, A.L., 2009. Enhancing hospital surge capacity for mass casualty events. JAMA, 302(5):565-567. [doi:10.1001/jama.2009.1119]

Rathbun, K.C., Cranmer, H., 2006. Hurricane Katrina and disaster medical care. New Engl. J. Med., 354(7):772-773. [doi:10.1056/NEJMc052957]

Rega, P., Burkholder-Allen, K., Bork, C., 2009. An algorithm for the evaluation and management of red, yellow, and green zone patients during a botulism mass casualty incident. Am. J. Disaster Med., 4(4):192-198.

Shen, J., Kang, J., Shi, Y., et al., 2012. Lessons learned from the Wenchuan earthquake. J. Evid.-Based Med., 5(2): 75-88. [doi:10.1111/j.1756-5391.2012.01176.x]

Takahashi, A., Ishii, N., Kawashima, T., et al., 2007. Assessment of medical response capacity in the time of disaster: the estimated formula of Hospital Treatment 
Capacity (HTC), the maximum receivable number of patients in hospital. Kobe J. Med. Sci., 53(5):189-198.

You, W.J., Zhang, Y.L., 2013. Research on index system of social vulnerability for flood hazard. J. Catastrophol., 28(3):215-220 (in Chinese).

Zhang, L., Li, H., Carlton, J.R., et al., 2009. The injury profile after the 2008 earthquakes in China. Injury, 40(1):84-86. [doi:10.1016/j.injury.2008.08.045]
Zhang, L., Liu, X., Li, Y., et al., 2012. Emergency medical rescue efforts after a major earthquake: lessons from the 2008 Wenchuan earthquake. Lancet, 379(9818):853-861. [doi:10.1016/S0140-6736(11)61876-X]

Zhou, J.H., Wang, Z.G., Huang, X.D., 2008. Injury characteristics of the earthquake-wounded and medical logistics management of Wenchuan County in "5.12" earthquake. Chin. J. Trauma, 24(7):488-490 (in Chinese). [doi:10. 3321/j.issn:1001-8050.2008.07.002]

\section{中文概要:}

本文题目: 大规模伤亡事件应对研究范式的发展: 基于汶川地震和杭州公交车起火事件紧急医疗救援 的反思

Development of the science of mass casualty incident management: reflection on the medical response to the Wenchuan earthquake and Hangzhou bus fire

研究目的：系统回顾大规模伤亡事件（MCI）经典研究范式, 结合 2008 年汶川地震和 2014 年杭州 7.5 公交车起火事件, 优化 MCI 应对的研究范式。

创新要点: 需求激增理论是 MCI 应对实时评估的显著进步, 结合 2008 年汶川地震和 2014 年杭州 7.5 公交车起火事件，我们发现 MCI 应对评估中一个非常重要的脆弱性因素被忽略。

研究方法: 采用关键词和医学主题词 (大规模伤亡事件、MCI、研究方法、汶川、地震、研究范式、激 增科学、激增、激增应对能力和脆弱性等), 通过检索数据库 PubMed、EMBASE、中国万 方及中国生物医学 (CBM) 的相关研究资料库, 进行理论的回顾性分析和结合实际案例的 分析。

重要结论：除需求激增理论中的激增和激增应对能力这二个基本维度外, 应引入第三个维度脆弱性, 形成更为全面和客观的三个互为关联维度构建 MCI 的新研究范式, 突破 MCI 传统研究范式 的局限性。

关键词组: 大规模伤亡事件; 需求激增; 脆弱性; 地震; 火灾 